\title{
Renewable Energy Technologies Penetration in MENA Region (2010-2030)
}

\author{
Marc Anthony Mannah, Loren Makki, Ahmad Haddad, Hassan Bazzi and Ali Hammoud \\ School of Engineering, Department of Electrical Engineering, Lebanese International University, Beirut, Lebanon
}

\begin{abstract}
This paper focuses on quantifying the renewable energy mix in the MENA (Middle East and North Africa) region and underlines its impact in terms of economic aspects. The installed and targeted capacities of solar, wind and other technologies will be revealed. In addition, distinguished present and on-going projects as well as prominent funding organizations are discussed. The overall strategy as well as the evolution of the renewable energy plan is resumed.
\end{abstract}

Key words: MENA, renewable energy, solar energy, wind energy, funding organizations.

\section{Introduction}

Ever since the industrial revolution evoked in the 18th century, immense capacities of fossil fuels have been utilized as a primary source to power the economy and prosper the global economic development. The steady yet expanding reliance on this finite, limited and contaminating source of energy resulted in accession of environmental concerns in the last decade, which prompted a number of energy conservation protocol measures that aim at enhancing the world's nourishment. The transition from finite, temporary and pollutant; to infinite, sustainable and clean energy resources was a fundamental objective worldwide, though it was somehow restricted by economic constraints. For the past fifty years, the MENA (Middle East and North Africa) region attained immense relevance as a global manufacturer and exporter of energy, having most of the world's crude oil and natural gas reserves. Therefore, the national energy market in the MENA region has been classified as negligible in the global frame, provided with sufficiently feasible, regionally created, low cost fossil-fuels [1]. As a result of the world's minimal

Corresponding author: Marc Anthony Mannah, Ph.D., assistant professor, PEM, research fields: power line communication, wind energy conversion system, renewable energy. E-mail: marc.mannah@liu.edu.lb. domestic costs for both initial energy and electricity, the MENA region confronted an absence of economic inducement essential for applying alternative energy resources like renewable, sustainable energy [2]. According to the OECD (organization for Economic Co-operation and Development) statistics, MENA cumulative energy demand is anticipated to extend superior to the world average, almost 3 percent per year; whereas the electricity demand is enlarging at a pace of 6 percent per year between 2010 and 2030 [1]. Fig. 1 reveals the excessive reliance of the MENA region on fossil fuels, relative to other districts.

As a consequence of the aforementioned dilemma, an imperative transition of fuel reliance should be achieved to perpetuate the economy and human welfare in the distant future.

By May 2013, all 21 MENA countries defined their renewable energy targets that would result in $107 \mathrm{GW}$ installed capacity by year 2030. Saudi Arabia alone aimed for an overwhelming $54 \mathrm{GW}$ by year 2032 [3]. This was agreed in the Copenhagen accord on climate and energy targets in 2009 that have come to endorse the continuation of the Kyoto Protocol.

The abundance of targets and protocols place solar Photovoltaic PV, concentrated Solar Power CSP and Solar Water Heating SWH as a preference indicating the high-quality solar energy resources in the area, and 
decreasing technology prices. As for the succeeding most prominent selection amongst renewable energy resources, comes wind energy [3]. Historically, the reliance was more on traditional renewable systems such as hydropower for used electricity generation and biomass used for cooking. However, currently, a deviation occurred reporting utmost projects are solar and wind.

In 2011, the share of renewable energy attained $3.3 \%$ of $1,200 \mathrm{TWh}$ of power generation in the MENA region. More recently, Morocco, Lebanon and Tunisia encountered and increased in their renewable energy contribution by at least 4 percentage points in years 2011 and 2012; reaching 33\%, almost $12 \%$ and $6 \%$ respectively in 2012 [3].

The condition of renewable energy in the MENA region is more compelling than in alternative geographic areas that are much more advanced in that field. This is due to the fact that the region has a fortunate climate and topography which devote immense capacity in the field of solar and wind energy. Thus, the application of renewable technologies will help in the reduction of environmental contamination, exploit oil and gas in further valuable means, improve positions as energy exporters and initiate enrolments [2]. Fig. 2 below shows the energy map of renewable energy in MENA region. These numbers account mainly for both solar and wind energies that are predominant $[3,4]$.

This paper discusses the state of solar, wind and other renewable technologies in the MENA region. Section 2 introduces the potential of solar technology in the MENA region by revealing current and targeted capacities, leading countries in the field, notable present and ongoing projects. Similarly, Section 3 presents the aforementioned subtitles regarding wind, hydro, biomass and geothermal power. Section 4 reveals the eminent funding organizations and the overall situation and perspectives. Finally, Section 5 presents a summarizing conclusion.

\begin{tabular}{|c|c|c|c|c|c|c|}
\hline & 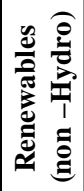 & 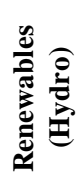 & $\frac{\tilde{\Xi}}{\tilde{\Xi}}$ & $\overline{0}$ & $\frac{\text { J }}{\stackrel{\tilde{J}}{\pi}}$ & $\overline{0}$ \\
\hline $\begin{array}{c}\text { Latin } \\
\text { America }\end{array}$ & $4 \%$ & $34 \%$ & $1 \%$ & $5 \%$ & $22 \%$ & $9 \%$ \\
\hline $\begin{array}{c}\text { Europe - } \\
\text { Central Asia }\end{array}$ & $6 \%$ & $14 \%$ & $19 \%$ & $21 \%$ & $26 \%$ & $1 \%$ \\
\hline $\begin{array}{c}\text { Sub Saharan } \\
\text { Africa }\end{array}$ & $1 \%$ & $17 \%$ & $3 \%$ & $47 \%$ & $6 \%$ & $2 \%$ \\
\hline $\begin{array}{c}\text { North } \\
\text { America }\end{array}$ & $3 \%$ & $10 \%$ & $17 \%$ & $35 \%$ & $16 \%$ & $4 \%$ \\
\hline $\begin{array}{c}\text { South } \\
\text { Asia }\end{array}$ & $2 \%$ & $12 \%$ & $2 \%$ & $50 \%$ & $14 \%$ & $5 \%$ \\
\hline $\begin{array}{l}\text { East Asia } \\
\text { Pacific } \\
\end{array}$ & $1 \%$ & $12 \%$ & $6 \%$ & $54 \%$ & $10 \%$ & $2 \%$ \\
\hline $\begin{array}{l}\text { MENA } \\
\text { Region }\end{array}$ & $1 \%$ & $2 \%$ & $0 \%$ & $3 \%$ & $56 \%$ & $25 \%$ \\
\hline
\end{tabular}

Fig. 1 Global fossil fuel shares in utility generation, 2010.

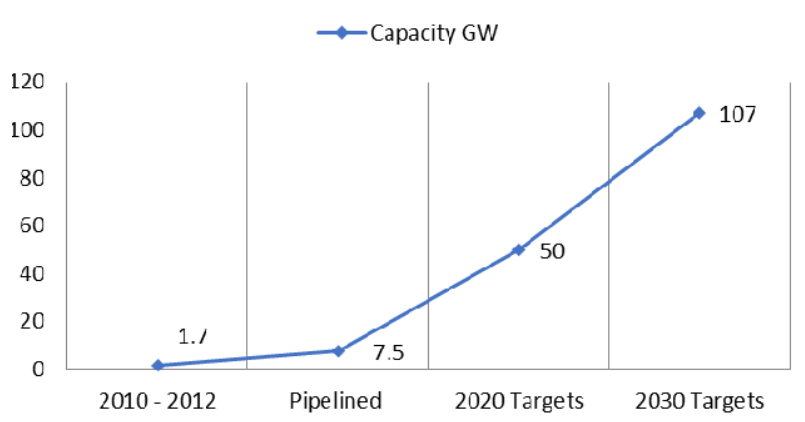

Fig. 2 MENA renewable energy roadmap 2010-2030.

\section{Solar Technology in MENA Region}

Despite the fact that wind energy grew into the largest renewable energy source following hydro power; solar power generation encountered progressive expansions in recent years. This tendency is anticipated to continue in the forthcoming future [3].

In addition, SWH (Solar Water Heating) systems are also an essential feature in the deployment of renewable technologies in the district. The installed capacities (MW) of PV and CSP by the end of 2012 are estimated to be around 182 and 407.64 respectively. However, according to Ref. [3], targets revealed up to 2030 exceed these numbers by far. The potential estimated for the MENA region for both PV and CSP is approximated to at least 26.4 and $39.7 \mathrm{GW}$ respectively. In this part, targets and capacities of 
leading countries in solar PV, CSP and SWH are revealed. Furthermore, the most eminent projects are discussed.

\subsection{Current Capacities}

Solar PV attained the ultimate average annual growth in power generation in MENA region in years 2008 till 2011 as debriefed in Fig. 3 [3]. We note a remarkable annual growth in solar PV resulting in an increased overall growth in renewable energy systems RES. Table 1 reveals the installed PV capacities in selected MENA countries by 2012 and 2013 [3, 4]. Only leading countries are shown.

As for CSP, it assists considerably to the escalating share of solar energy in the region. In 2011, 40\% of the countries running CSP plants were localized in the MENA region, particularly Algeria, Egypt Iran and Morocco having integrated solar combined cycle (ISCC) technologies [4]. In 2013, these countries were united with UAE. Currently, UAE became the dominant participant in the CSP market having Shams 1, the largest CSP plant with a capacity of $100 \mathrm{MW}$ operating since March 2013. Table 2 below reveals the installed CSP capacities in MW in selected MENA countries in 2012 and 2013 [3, 4]. On the other side, solar water heating systems SWH are also a vital element in the distribution of renewable technologies in the region. By 2013, they accounted for approximately 9 million square meters $\left(\mathrm{m}^{2}\right)$ of collector area serving 6.3 gigawatts-thermals $\left(\mathrm{GW}_{\text {th }}\right)$ of installed capacity. The PROSOL program in Tunisia was a prosperous regional attainment having more than $500,000 \mathrm{~m}^{2}$ of installed surface [5].

In addition, the PROMASOL program in Morocco had $240,000 \mathrm{~m}^{2}$ of surface equipped with SWH panels in 2008 although the target was only $100,000 \mathrm{~m}^{2}$ [6].

Eminent SWH installed capacity and the corresponding collector area for specific MENA countries in 2012, are shown in Table $3[3,4,7]$.

\subsection{Targets and Potentials}

Notable solar PV and CSP capacity targets set by

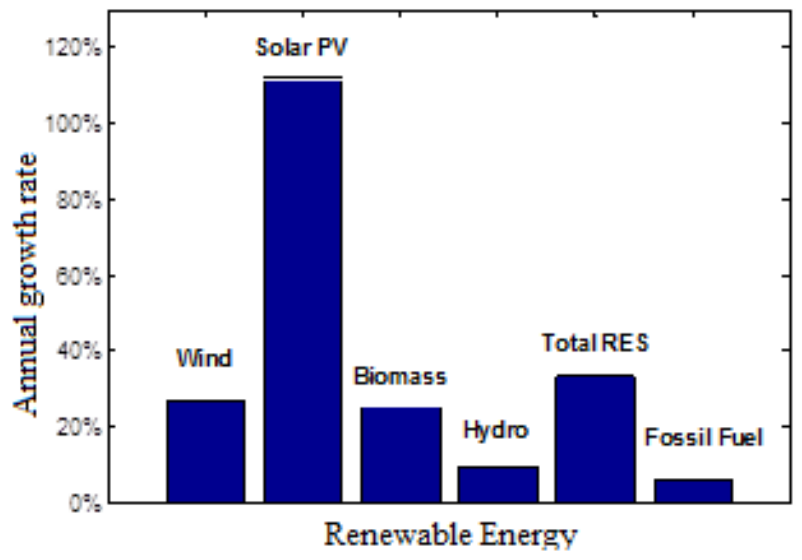

Fig. 3 Annual growth rate of renewable energy in MENA.

Table 1 Installed PV capacity in MENA countries.

\begin{tabular}{ll}
\hline Country & PV (MW) \\
\hline Egypt, Morocco & $15(2012)$ \\
Saudi Arabia & $19(2013)$ \\
UAE & $33(2013)$ \\
Yemen & $3(2013)$ \\
Israel & $269(2012)$ \\
\hline
\end{tabular}

Table 2 Installed CSP capacity in MENA countries.

\begin{tabular}{ll}
\hline Country & CSP (MW) \\
\hline Algeria & $25(2012)$ \\
Egypt, Morocco & $20(2012)$ \\
UAE & $100(2013)$ \\
\hline
\end{tabular}

Table 3 Installed capacities of SWH systems.

\begin{tabular}{lll}
\hline Country & $\begin{array}{l}\text { Capacity } \\
\left(\mathrm{MW}_{\mathrm{th}}\right)\end{array}$ & $\begin{array}{l}\text { Collector Area } \\
\left(\mathrm{m}^{2}\right)\end{array}$ \\
\hline Egypt & 525 & 750,000 \\
Israel & $2,917.8$ & $4,168,245$ \\
Palistinian Territories & 1,120 & $1,600,000$ \\
Tunisia & 437.5 & 625,000 \\
\hline
\end{tabular}

MENA region vary among the different countries. Some have defined their plans up to year 2020, others 2030 or within that range.

In Table 4, only selected MENA countries are listed [3]. Those countries were cited among others as they are considered as leaders in this field. Also, Table 5 reveals targeted SWH capacities by selected MENA countries $[3,4,7]$.

\subsection{Current and Forthcoming Projects}

In the past years, the MENA region attained a compelling advancement in the solar energy sector via 
Table 4 Solar capacity targets in MENA.

\begin{tabular}{llll}
\hline Country & Year & PV (MW) & CSP (MW) \\
\hline Algeria & By 2030 & 2,800 & 7,200 \\
Kuwait & By 2030 & 3,500 & 1,100 \\
Saudi Arabia & By 2032 & 16,000 & 25,000 \\
\hline
\end{tabular}

Table 5 SWH targets in MENA countries.

\begin{tabular}{lll}
\hline Country & Year & SWH target \\
\hline Lebanon & By 2020 & $1,050,000 \mathrm{~m}^{2}$ of collector area \\
Morocco & By 2020 & $1,700,000 \mathrm{~m}^{2}$ of collector area \\
\hline
\end{tabular}

actual project settlements and projected objectives. Vast developments have been achieved in alternative countries engulfing the world's most innovative projects. The following section will highlight the most appealing projects and the forthcoming targets in selected countries.

Let us start first with the eminent present and ongoing projects. According to Refs. [8, 9], the most notable solar projects are concentrated solar power type and take place in UAE, Morocco and Tunisia. Table 6 resumes these projects and lists their capacities.

In terms of prominent forthcoming projects, by April 2013 some MENA countries have defined an estimated solar capacity (MW) relative to their pipelined projects. The number of these projects are disclosed between parentheses and revealed in the bar chart below in Fig. 4 [3]. Israel is leading in terms of number of projects followed by Oman and Jordan. Table 7 below reveals some of the eminent upcoming projects $[8,10]$.

\section{Wind and Other Technologies in MENA Region}

Adapting a complex climate model, researchers declare that the MENA region acquires valuable prospects for wind energy. The abundance of wind available is competent to supply half to several times the world's total energy needs within the coming two decades [11].

The development of wind projects across the MENA region is flourishing mainly by including two of the
Table 6 Notable solar projects.

\begin{tabular}{llll}
\hline Project & Type & Capacity (MW) & Country \\
\hline Shams 1 & CSP & 100 & UAE \\
Quarzazate & CSP & 160 & Morocco \\
$\begin{array}{l}\text { South-West of } \\
\text { Tunisia }\end{array}$ & CSP & 2,000 & Tunisia \\
\hline
\end{tabular}

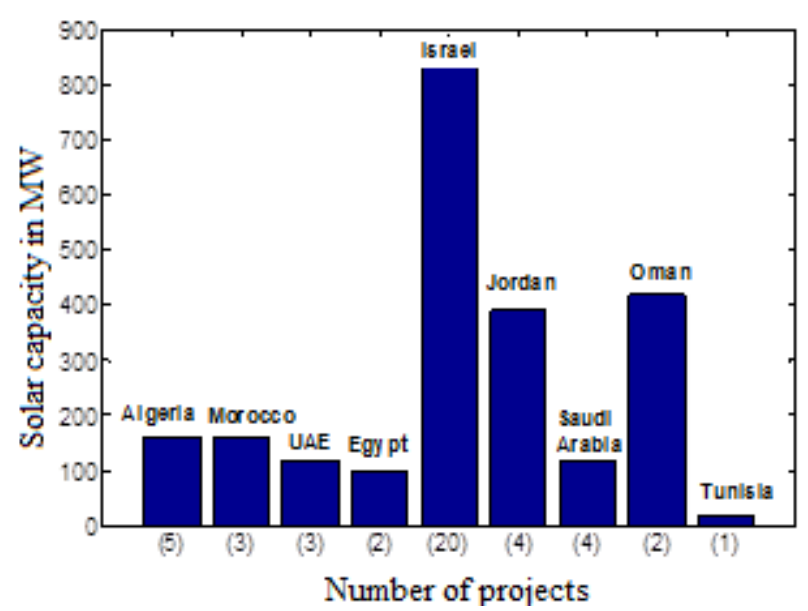

Fig. 4 Solar capacity targets and pipelined projects.

Table 7 Noted upcoming solar projects.

\begin{tabular}{llll}
\hline Project & Type & Capacity (MW) & Country \\
\hline Shams Ma'an & PV & 100 & Jordan \\
K.A.CARE & PV \& CSP & 4,500 & Saudi Arabia \\
Kisr phase 1 & PV \& CSP & 4,000 & Kuwait \\
\hline
\end{tabular}

world's largest wind farms in Morocco and Egypt. Nevertheless, amongst non-hydro renewable power, wind dominates renewable energy ongoing and forecasted projects [3].

In terms of definite numbers, hydropower preserves the leading renewable energy source in the MENA region presently. As for other technologies, modern biomass and geothermal power are the minimal utilized energy sources in the region in term of deployment [3].

\subsection{Current Capacities}

The installed power capacities of wind, hydro, biomass and geothermal renewable energy resources by the end of 2012 are 1,094.40, 17,653, 73.5 and $0.023 \mathrm{MW}$ respectively. The capacity and potential of wind and other technologies will be revealed.

After hydro, wind energy is the most prevalent source of electricity production in the region, 
particularly in Egypt, Morocco and Tunisia. By the end of year 2012, partly eight MENA countries had a total of approximately $1.1 \mathrm{GW}$ of wind power capacity. Egypt is the head in the sector having 550 MW installed capacity, followed by Morocco with 291 MW and Tunisia with 154 MW [3]. The utmost appealing growth rate of wind power was bounded between years 2005 and 2010 as shown in Fig. 5 [3].

The strongest growth in wind power took place between 2005 and 2010, with a more than fourfold increase in total installed capacity. Recent socio-political events linked to the Arab Spring in some parts of the MENA region seem to have slowed down the promising and rather widespread development of wind [3].

Table 8 shows notable installed wind capacities in selected MENA countries for wind energy in year $2012[3,4,7]$.

As for hydropower, it is the dominant energy source for electricity generation in the MENA region with the installed capacities in 2012 revealed in Table 9 [3, 4, 7]. The overall capacity in the MENA region by this year was approximated to $17.653 \mathrm{GW}$.

Regarding biomass and waste power capacities the eminent installed capacities for year 2012 is estimated to be around 73.5 MW in the MENA region. Leading countries are Qatar with $40 \mathrm{MW}$ and Israel with 27 MW. The only country having geothermal capacity installed in the MENA region is the Palestinian territories with only $0.023 \mathrm{MW}[3,4,7]$.

\subsection{Wind and Other Technologies' Capacity Targets}

Notable capacity targets by selected MENA countries are revealed below in Table $10[3,4,7]$. Though the targets of each country vary function of the year, the only available numbers estimate an overall capacity of wind energy of around $32.64 \mathrm{GW}$ by year 2030. Regarding other technologies (Biomass, geothermal and hydro) the estimated target by year 2030 for all MENA countries is around 8.32 GW.

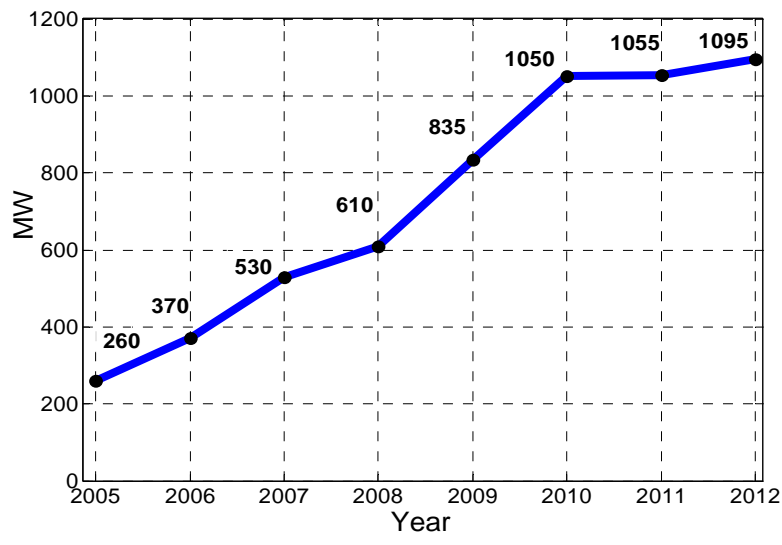

Fig. 5 Wind power growth rate between 2005 and 2012.

Table 8 Installed wind power in MENA.

\begin{tabular}{ll}
\hline Country & Wind (MW) \\
\hline Egypt & 550 \\
Morocco & 291 \\
Tunisia & 154 \\
Iran & 91 \\
\hline
\end{tabular}

Table 9 Installed hydro power.

\begin{tabular}{ll}
\hline Country & Hydro (MW) \\
\hline Egypt & 2,800 \\
Iran & 9,500 \\
Iraq & 1,864 \\
Morocco & 1,745 \\
\hline
\end{tabular}

Table 10 Wind and other technologies' capacity targets in MENA region.

\begin{tabular}{llll}
\hline Country & Year & Wind (MW) $\begin{array}{l}\text { Biomass, } \\
\text { geothermal and } \\
\text { hydro (MW) }\end{array}$ \\
\hline Algeria & By 2030 & 2,000 & - \\
Egypt & By 2020 & 7,200 & - \\
Kuwait & By 2030 & 3,100 & 1,100 \\
Saudi Arabia & By 2032 & 9,000 & 4,000 \\
Syria & By 2030 & 2,000 & 400 biomass \\
Morocco & By 2020 & 2,000 & 2,000 hydro \\
\hline
\end{tabular}

\subsection{Current and Forthcoming Projects}

This section will highlight some of the intriguing projects and reveal the forthcoming targets in selected countries.

Eminent present and ongoing projects are revealed in Table 11 [9, 12-15]. However, the current capacity exceeds these numbers by far. Current hydro capacity in MENA region is estimated to $4.1 \mathrm{GW}$ with Egypt 
and Morocco having the lead. Current wind capacity is estimated to $0.9 \mathrm{GW}$ with Egypt and Tunisia on the lead. Biomass and other technologies account for around $1 \mathrm{GW}$.

Regarding the forthcoming projects related to wind and other technologies, the already pipelined ones are estimated to provide about $5 \mathrm{GW}$ of clean energy. Wind energy projects estimated o around 45 provide approximately $4.74 \mathrm{GW}$. The other $0.26 \mathrm{GW}$ are divided among biomass and waste (12 projects), Geothermal ( 2 projects) and small hydro (1 project) [3]. As for biomass energy, the residual municipal, agricultural and industrial biomass in Morocco attained $950 \mathrm{MW}$ of electrical production btw 2012, 2014 [16]. Also a $10 \mathrm{MW}$ waste-to-electricity project at the Jebel Chakir landfill in Tunisia has been implemented [15]. In terms of biogas capacities, Jordan was the leading country with capacities up to almost $10 \mathrm{MW}$ through two main projects, the Russaifa (3.5 MW) and the Samra (6 MW) [17].

Pipelined renewable technologies in terms of capacity are revealed in Fig. 6 [3]. In terms of technology and availability, wind and solar energies account for around $42.5 \%$ and $41.5 \%$ respectively. Some of the most noted forthcoming projects, we note the "Abu Dhabi Waste-to-energy" project that has a capacity of $100 \mathrm{MW}$ and the "K. A. CARE" project in Saudi Arabia that targets 1,700 MW in terms of wind and $700 \mathrm{MW}$ in terms of other technologies [8]. Taxes that may be paid are not taken into consideration, too.

\section{Funding Strategies}

With ample renewable energy projects in the pipeline in the MENA region, funding constituting of durable, low-interest loans remains an essential source for the abundant renewable projects.

The main contributors in the region are the German Development Bank (KfW), World Bank Group, United Nations Development Programme (UNDP), United Nations Environment Programme (UNEP) International Bank for Reconstruction and Development (IBRD), the African Development Bank (ADB) which play a significant role in the district.

Table 11 Notable present and ongoing projects.

\begin{tabular}{llll}
\hline Project & Type & Capacity (MW) & Country \\
\hline Zafarana & Wind & 550 & Egypt \\
High Dam & Hydro & 2,100 & Egypt \\
Bizerte & Wind & 186 & Tunisia \\
Jebel Chakir & Biomass & 10 & Tunisia \\
\hline
\end{tabular}

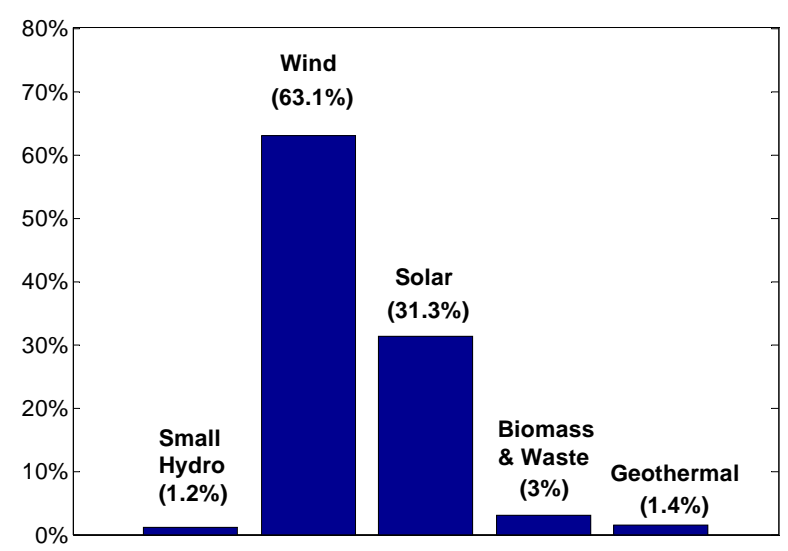

Fig. 6 Pipelined renewable energy projects by capacity.

Table 12 Benefactors and beneficiaries of some renewable projects in MENA region.

\begin{tabular}{|c|c|c|c|}
\hline Benefactor & Beneficiary & Budget & Project \\
\hline $\begin{array}{l}\text { World Bank } \\
\text { (EIB, UNDP and UNEP) }\end{array}$ & MENA countries & MUSD 2,100 & 17 various projects \\
\hline Abu Dhabi Fund for Development & Algeria, Yemen & $>$ MUSD 350 & Restricted for IRENA members \\
\hline $\mathrm{CTF}$ & Algeria, Egypt, Jordan, Morocco, Tunisia & MUSD 947 & $1 \mathrm{GW}$ CSP + Quarzazate project \\
\hline $\begin{array}{l}\text { ACWA Power International } \\
\text { Banque Centrale Populaire }\end{array}$ & Morocco & MUSD 1,160 & Quarzazate CSP project \\
\hline $\begin{array}{l}\text { Attijariwafa Bank } \\
\text { Nareva Holdings SA }\end{array}$ & Morocco & MUSD 563 & Tarfaya Wind Farm (300 MW) \\
\hline Consortium of banks & Egypt's NREA & MUSD 455.5 & $\begin{array}{l}\text { NREA and Gulf of EL Zeit Wind farms } \\
(200 \mathrm{MW})\end{array}$ \\
\hline
\end{tabular}


In addition, the EIB (European Investment Bank), the AFD (French Development Agency), Abu Dhabi Fund for Development, and the CTF (Clean Technology Fund) are also dominant participants in the region [3]. The following table underlines the economical strategy adopted by revealing the main grants and funding attributed to the MENA region. The main benefactors of the projects in the MENA region, the beneficiary countries, and the given budget in Millions of Dollars (MUSD) are all presented. Grants are allocated for different type of projects including but not limited to, hydro, geothermal, wind solar (PV, CSP, and SWH)...

In terms of the criteria considered for funding of the renewable energy projects in the MENA region, the GCF (Green Climate Fund) has intended to channel support to the developing world to address climate change, with the goal of mobilizing USD 100 billion annually in climate finance by 2020 from both public and private investors. Progress is being made in the definition of the GCF business model framework. In March 2013, its Board agreed that the "Fund should follow a country-driven and owned approach as a core principle, and should leverage additional resources, including through a private sector facility." The NAMAs (Nationally Appropriate Mitigation Actions) has mitigated greenhouse gas emissions in developing countries that are not subject to mitigation commitments, and these actions can be supported by industrialized countries through financing, technology transfer, or capacity building.

\section{Conclusion}

Despite the fact that the deployment of renewable energies in the MENA region is considerably hindered by socio-economic factors, the advancement of the renewable energy sector in the past years has been compelling.

Acquiring prime solar energy conveniences in the arena, solar expansion is expected to be substantial both in CSP and PV and may dominate wind energy by 2020 , mainly with Saudi Arabia's vital solar schemes. As for the consecutive renowned renewable energy resource, comes the wind energy. The enrollment of wind energy is outstanding mainly in Egypt, Morocco and Tunisia.

By the end of 2012, the installed renewable capacity in MENA region attained a value of $19 \mathrm{GW}$; whereas, the objective set by all 21 MENA countries is to attain a target of $107 \mathrm{GW}$ by 2030 . This is most likely to be accomplished by climate and private funding organizations that have shown serious involvement following the Copenhagen agreement in 2009. In regards to forthcoming research opportunities, this survey could be extended in order to exploit the advancements in the overall energy plan and the evolution of the preplanned projects, hence evaluating the renewable power blend in the MENA region up to 2050.

\section{References}

[1] El-Katiri, L. 2014. "A Roadmap for Renewable Energy in the Middle East and Africa." OIES paper: MEP 6. The Oxford Institute for Energy Studies.

[2] El-Sayed, T. 2010. "A New Source of Power the Potential for Renewable Energy in the MENA Region." Abu Dhabi.

[3] Bryden, J. 2013. "MENA Renewables Status Report."

[4] El-Khayat, M. 2014. "Pan-Arab Renewable Energy Startegy 2030 Roadmap of Actions for Implementation." IRENA in Collaboration with the League of Arab States and Produced by RCREEE.

[5] Avato, P. 2013. "Investment Potential in EMENA." IFC.

[6] Allali, I. 2011. "PROMASOL: Democratizing Access to Solar Water-Heaters." Growing Inclusive Markets, Morocco.

[7] Abdel, G. I. 2013. "Arab Environment Sustainable Energy Prospects, Challenges, Opportunities." AFED with Technical Publications and Environment \& Development Magazine, Beirut, Lebanon,

[8] Connor, K. 2013. "The Future for Renewable Energy in the Mena Region." Squire Sanders.

[9] Swenacc. 2014. "Renewable Energy Sector in the Maghreb." Swenacc.

[10] MEED Insight. 2014. "Mena Solar Power Market and Projects Report 2014.” MEED. 
[11] Mayton, J. 2012. "Who's Got the Wind Power in the Middle East?" Green Pro et.

[12] Abdel, A. A. F. 2011. "Studying of Wind Farm Performance at Zafarana Egypt." International Journal of Electrical \& Computer Sciences IJECS-IJENS: $42-51$.

[13] Liu, H., Masera, D., and Esser, L. 2013. "World Small Hydropower Development Report 2013 EGYPT." United Nations Industrial Development Organization (UNIDO) and International Center on Small Hydro Power (ICSHP).

[14] Saidin, L., and Fnaiech, F. 2014. "Experiences in
Renewable Energy and Energy Efficiency Tunisia: Case Study of a Developing Country." Renewable and Sustainable Energy Reviews: 729-38.

[15] Bradley, A. 2011. "Expansion of Electricity Production includes Green Energy." Tunisia Live.

[16] Ettaik, Z. 2013. "Renewable Energy in Morocco: Large-Scale Deployment." Ministry Of Energy Mines Water and Environment, Casablanca.

[17] Ahmad Al-Rousan. 2013. "Biomass Potential in Jordan and Future Research Prospects." National Energy Research Center Studies and Consultations Specialist, Amman-Jordan. 